\title{
VLA-LÁCTEA DE GÔZÔ YOSHIMASU O POETA E A IMENSIDÃO
}

Valdinei Dias Batista

\begin{abstract}
A voz, set frágil e efémero, pode testemunhar as mais fones realidades. [.../ Mas, antes de falar, é preciso ouvir.

Gaston Bachelard, A Poética do Espaço

A condição humana: ultrapassá-la.

Mas como recriar

outra harmonia?

Carlos Nejar, "Só Conheço Deus", A Árvore do Mundo
\end{abstract}

\section{VLA-LACTEA}

Um homem lavando sua camisa. Lavando a fina e bela veste de brilho metálico enquanto pensa a respeito do cosmo. Música escorrendo. No fundo da cisterna tremulam algas; os dedos dentro dágua rabiscando curvas, desenhando veios. Ah! a febre do cosmo primitivo afeta o corpo humano e os dedos afligem-se pela frieira. Nunca mais contornar o universo feito barco, desenhan- 
do curvas, torcendo cabelos. Tanto às segundas como às quartas, banha-se. Tanto às segundas como às quartas, banha-se. Tardio outono; frente à casa crescem os frutos vermelhos da nandina. Num lugar de encontro qualquer, um homem lavando sua camisa. Como de costume, como se alguém ali estivesse, tagarela. Ele não canta. Apenas lava a fina e bela veste de brilho metálico. $\mathrm{E}$ logo, tanto as estrelas como a alta árvore e a lembrança da bela fêmea mergulharão no fundo da via-láctea salpicada de neve, feito bolhas. $\mathrm{Na}$ água, fincado o dedo ardente! Um, dois versos golpeiam o céu. Então, não se teriam passado milhares de anos? Como antes, o homem lavando uma camisa. Era uma veste para a derradeira viagem, esbranquiçadamente carmesim. E logo, o homem, pouco a pouco, começou a arregaçar as mangas.

(tradução: Valdinei Dias Batista)

Um belíssimo conto zen - um koan - conta-nos a respeito de certa candidata a monja que, costumeiramente, saia à noite para retirar água dum poço, com um balde feito de ripas de madeira. A mulher, diz-nos o narrador, encantava-se, toda vez, com o reflexo da lua na superfície da água do balde, e de tal maneira se encantava, que cria ver na superfície da água a verdadeira lua, ignorando, desta maneira, a lua verdadeira resplandecendo na noite escura. Certa noite, ainda fascinada pela lua-reflexo da superfície da água do balde, eis que este lhe escorregou das mãos, espatifando-se no chão, espalhando toda água colhida. Assim - e é esse o "ponto nevrálgico" do koan - nem água nem lua sobraram-lhe.

A personagem criada por Yoshimasu no poema Via-Láctea lava sua mortalha branca - já quase carmesim - e por intermédio do reflexo na água da cisterna, "pensa a respeito do cosmo", ou seja, vislumbra a Via-Láctea refletida na superfície da água, como num espelho.

Poesia é por si só sugestão.

$E$, na verdade, toda a ambiência do poema em questão sugere um jogo de espelhos, de reflexão "em abismo":

Um homem lavando sua camisa. Lavando a fina e bela veste de brilho metálico enquan- 
to pensa a respeito do cosmo. Música escorrendo. No fundo da cisterna tremulam algas; os dedos dentro dágua rabiscando curvas, desenhando veios.

Aliás, a utilização, pelo poeta, duma personagem-agente - no plano de sua imaginação lírica - já é, por si só, a primeira imagem refletida do poema:

Um homem lavando sua camisa.

O poeta se reflete no homem, este se reflete na superfície especular da cisterna; esta reflete a galáxia e a imensidão do cosmo. Voltamos, desse modo, nas mãos do poeta, ao tempo indiviso, ao caos primordial (o "cosmo primitivo"), "quando o Espírito boiava sobre as águas". Pura vertigem e abismo.

O vórtice sugerido pelo poema é, na realidade, formado por pura cor e movimento. A mortalha branca de brilho metálico vai, pouco a pouco, tornando-se carmesim, quem sabe se pelo sangue que brota das mãos da personagem, friccionando a mortalha entre os dedos; o prateado da Via-Láctea refletido na água da cisterna, misturado aos revérberos metálicos da veste; as algas tremulantes, talvez verdes, no fundo dágua; os frutos vermelhos da nandina e a cor outonal da árvore que se reflete, também, na água. Tudo gira em curvas, ondas, movimentado pelas mãos do homem.

No espaço sideral, escorre a Via-Láctea com seu brilho metálico (ginga, a palavra japonesa para Via-Láctea, significa, literalmente, rio de prata), em movimentos ondulantes, sobre uma superfície negra. $O$ homem, ao lavar sua mortalha, produz o mesmo movimento: as algas tremulam e os dedos rabiscam curvas e desenham veios, reproduzindo, no fundo dágua, a mesma Via-Láctea. Percebemos, ainda, as impressões digitais do homem, semelhando veios de madeira. Todo o ambiente, todas as coisas parecem circunvagar, até mesmo a música, no ar, escorrendo; e o vórtice cresce de forma amplificada.

Surpreendentemente notamos, então, pelo reflexo na superfície dágua, que o homem, ao lavar sua mortalha, age como se amassasse, moldasse, torcesse e amalgamasse sua morte futura e o pequeno espaço da cisterna à imensidão da Via-Láctea e esta fosse, afinal, sua própria "veste para a derradeira viagem" $O$ eterno retorno ao caos?

É próprio de Yoshimasu essa rápida escapadela para o alto, para o espaço, fundindo caos e cosmo. No livro Doido na Manhã, no poema "Vamos Voltar", o poeta, ciente da impossibilidade de "pedir um fogo para seres civilizados, como os homens", produz a partir do cerne de sua própria alma cansada um remo

Que atravessará mares revoltos,

Abrindo caminho por entre estrelas, penduradas no céu da noitel.

1. Traduçāo de Jô Takahashi. 
Em "Vamos Voltar", o espaço sideral, refletido na superfície do oceano noturno, termina por se fundir numa só superfície que o poeta singra com seu remo anímico. Essa mescla, essa fusão do espaço sideral e do oceano parece ser a única solução para recriar a harmonia sobre a Terra. Outra poeta, também afeita às superfícies especulares e ao misticismo, Cecilia Meirelles, já dissera que "a vida só é possível reinventada".

Em Yoshimasu essa imagem da "fuga" retornará no poema "Círculo de Pedra", do livro Osíris - o Deus de Pedra, um poema insólito, denso e deveras imagético:

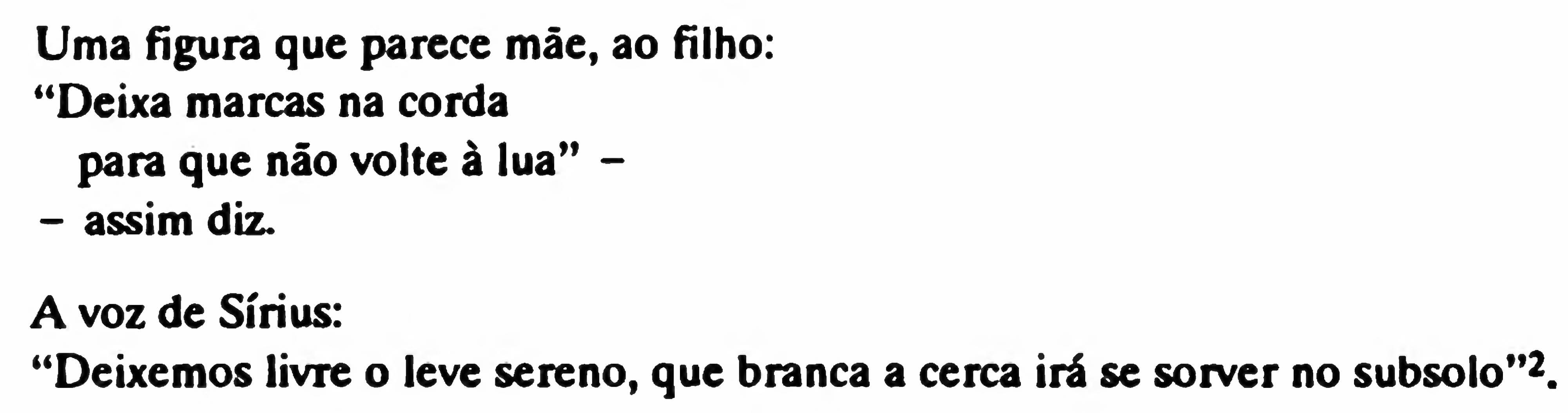

Aqui, parece que, como num corte súbito, cinematográfico, a ação que se desenvolve no nível do chão (o Círculo de Pedra em si) alteia-se ao espaço sideral, tocando a estrela Sírius.

A pequenez abre-se à amplidão. lard:

Em $A$ Poética do Espaço, Cap. VII, “A Miniatura”, diz-nos Gaston Bache-

[...] A imaginação miniaturizadora é uma imaginação natural. Aparece em todas as idades do devaneio dos que nasceram sonhadores. Precisamente, é preciso separar o que diverte para descobrir aí raízes psicológicas efetivas. [...] Quantas vezes o poeta-pintor, na prisão, não perfurou as paredes por um túnel! Quantas vezes, curtindo seu sonho, não se evadiu por uma fenda da parede! Para sair da prisão, todos os meios são válidos. Precisando-se, o absurdo é capaz de libertar.

Em Via-Láctea, Yoshimasu parte do espelho na superfície da água da cisterna e do minúsculo ato de lavar uma camisa, para a amplidão da Via-Láctea, num átimo. É como a fuga da prisão de que nos falou Bachelard. A própria estruturação do poema é econômica, enxuta, curta, minúscula, mesmo. A partir dum curto texto, o poema se abre para a imensidão do cosmo, mimetizando a dialética pequeno/imenso.

$\mathrm{Na}$ realidade, já a partir do trecho:

E logo, tanto as estrelas como a alta árvo-
re e a lembrança da bela fêmea mergulharão
no fundo da via-láctea salpicada de neve,
feito bolhas,

2. Traduçāo de Antonio Nojiri. 
o espaço sideral, o futuro (o que mais representaria a branca mortalha?), o presente (o ato praticado pela personagem, a árvore), o passado (a lembrança da bela fêmea) se fundem em definitivo (restando ao homem "arregaçar as mangas" e partir para a luta). Preparando-se para a morte, a personagem do poema abre seu ato à amplidão e - como um deus - estende seu trabalho à Via-Láctea.

A paisagem é simples: uma casa qualquer, um lugar de encontro qualquer, talvez nem tão vasto. A nandina (planta originariamente chinesa) principia a dar frutos - outono tardio. Tempo de queda e de renovação a um só tempo.

Sozinho, tagarelando, um homem lava sua mortalha - ele não canta, mas há música escorrendo, circunvagando o ar. Tanto a água fria quanto a friç̧ão (que mostra certa ansiedade por parte da personagem) produzem frieira nos dedos e a ação parece transcorrer num tempo impreciso, talvez milhares de anos. Tudo isso é ação imaginária. Tudo, até aqui, ocorre por transposição de imagens e por reflexão. Água, algas, camisa, árvore, estrelas, lembranças; tudo fundido, num espaço pequeno, desembocando - como no espelho de Alice no espaço incomensurável do Universo.

E logo, o homem, pouco a pouco, começou a arregaçar as mangas,

em suma, salta do plano da pura imaginação para o plano da práxis concreta.

Diz-nos Alfredo Bosi no ensaio $O$ Encontro dos Tempos:

A poesia, que se faz depois da queda, é a linguagem da suplência. Primeiro coral, depois ressoante no peito do vate que se irmana com a comunidade, enfim reclusa e posta à margem da luta, a sua voz procura ministrar aos que a ouvem o consolo do velho canto litúrgico, aquele sentimento de comunhão do homem com os outros, consigo, com Deus.

A poesia de Gôzô Yoshimasu é tanto estruturada com múltiplas imagens imbricadas umas nas outras - e, portanto, visual - quanto articulada com palavras, por vezes esvaziadas semanticamente, feita, no mais das vezes, para declamação. Basta, no original, muito mais do que na tradução, tomar atenção à sonoridade e à percussão fonética - o batuque - das palavras no poema. Os que já tiveram a oportunidade de ouvi-lo declamar seus poemas sentiram toda a estranheza de sua declamação - por vezes desesperada - conseqüência do seu "fazer poético" Assim, creio, torna-se inevitável aproximar a estranheza de sua espécie de declamação ao "tagarelar" da personagem, à beira da cisterna, onde, após isso:

\section{Um, dois versos golpeiam o céu.}

O tagarelar da personagem (que lembra as ladainhas litúrgicas ocidentais, mas também as similares budistas, aos nossos ouvidos) parece partir da boca da personagem - quase disse poeta - e se elevar no ar, rumo, ela também, à Via-Láctea, à imensidão. Tudo converge do pequeno para o imenso. 
Talvez a principal beleza do pocma resida nessa dialética pequeno/imenso. $O$ poema é, estruturalmente, como já disse, pequeno, resumido, mesmo. Assim como o ambiente em que tudo ocorre. No entanto, a partir desse ponto minúsculo, dessa pequena fenda, abre-se a imensidão do cosmo, escorre a música e a Via-Láctea e tudo no poema gira, como o mecanismo de um imenso relógio - o poema resume-se, então, no tempo. E o grito agônico do sonhador frente a um mundo perverso que oscila entre o bem e o mal, o pequeno e o vasto, homens e deuses, passado e futuro.

Nesse sentido, Yoshimasu pode ser aproximado, pela sua agonia lírica, à do brasileiro-gaúcho Carlos Nejar, do poema que serve de epígrafe a este texto, "Só Conheço Deus":

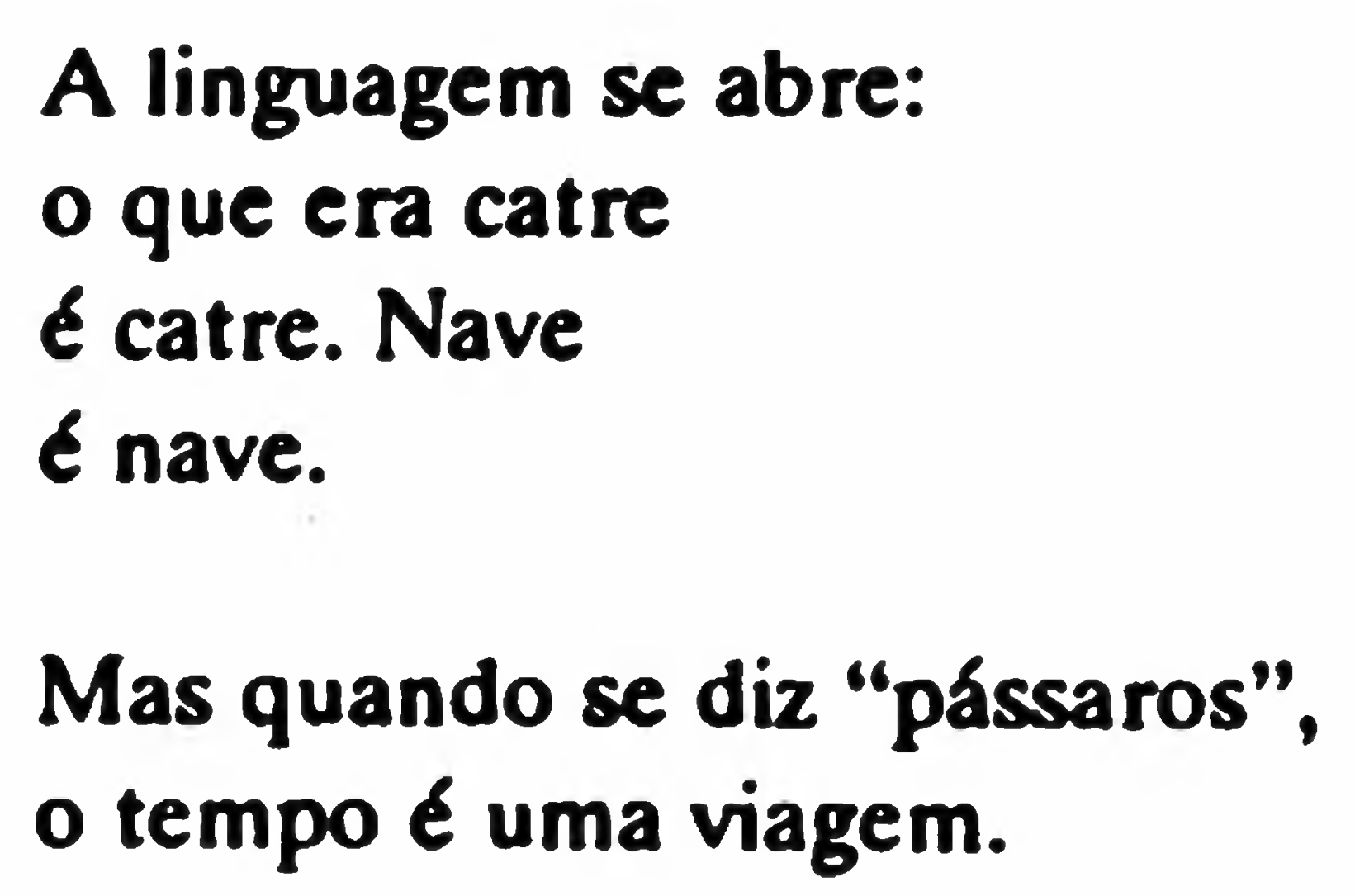

Nessa abertura para a imensidão - que vemos em Via-Láctea de Yoshimasu, tanto quanto em Nejar, a linguagem se abre para o tempo incomensurável; o espaço se abre para a vertigem do infinito; a audição se abre para o fogo da fala; a agonia se prostra frente à harmonia e rende-se a ela. Dante e Moisés perante a figura de Deus. Bashô frente as campinas secas:

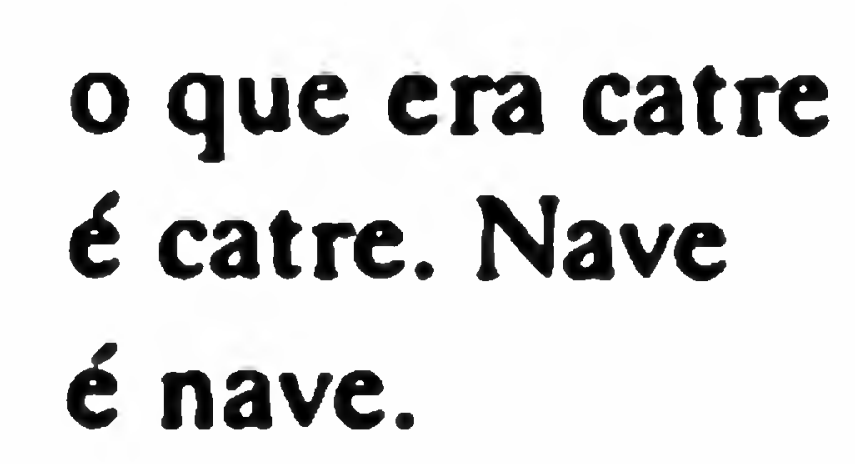

O mundo resta, liricamente renovado, como no sexto dia da criação.

$O$ poeta transcende à mesquinhez da monja do conto zen rompendo a dualidade tempo/espaço: tanto água como lua.

\section{Bibliografia}

Bachelard, Gaston. "A Poética do Espaço". Os Pensadores, 2a ed. São Paulo, Abril Cultural, 1984.

Bosı, Alfredo. "O Encontro dos Tempos". O Ser e o Tempo da Poesia. São Paulo, Cultrix, 1977. Yoshimasu, Gôzô. Doido na Manhā (trad. Jô Takahashi). Rio de Janeiro, Numen, 1985.

Osínis - o Deus de Pedra (trad. Antonio Nojiri). Sảo Paulo, Aliança Cultural BrasilJapão/Estação Liberdade, 1993.

Oshirisu, ishi no kami, Tokyo, Shinchôsha, 1984. 
(Poema da 4 capa)

Era uma blusa de um lilás suave.

Bela montanha.

Osiris

o Deus de Pedra

'92

Gôzô Yoshimasu 